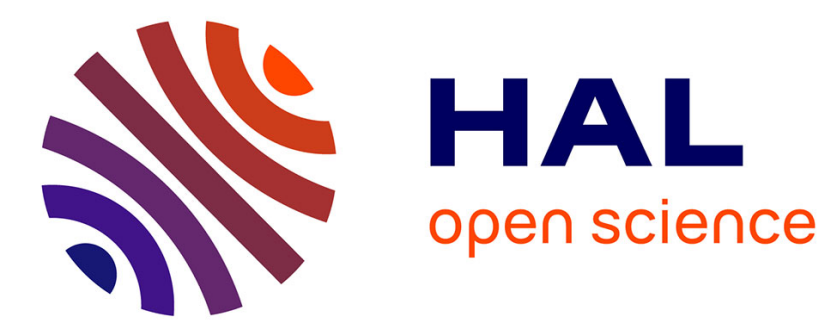

\title{
A colour assessment methodology for oak wood
}

Defoirdt, Wuijtens, de Boever, Coppens, van den Bulcke, van Acker

\section{To cite this version:}

Defoirdt, Wuijtens, de Boever, Coppens, van den Bulcke, et al.. A colour assessment methodology for oak wood. Annals of Forest Science, 2012, 69 (8), pp.939-946. 10.1007/s13595-012-0214-3 . hal00930864

\section{HAL Id: hal-00930864 \\ https://hal.science/hal-00930864}

Submitted on 1 Jan 2012

HAL is a multi-disciplinary open access archive for the deposit and dissemination of scientific research documents, whether they are published or not. The documents may come from teaching and research institutions in France or abroad, or from public or private research centers.
L'archive ouverte pluridisciplinaire HAL, est destinée au dépôt et à la diffusion de documents scientifiques de niveau recherche, publiés ou non, émanant des établissements d'enseignement et de recherche français ou étrangers, des laboratoires publics ou privés. 


\title{
A colour assessment methodology for oak wood
}

\author{
Nele Defoirdt • Inge Wuijtens • Lieven De Boever • \\ Hugo Coppens • Jan Van den Bulcke • Joris Van Acker
}

Received: 16 December 2011 / Accepted: 30 April 2012 /Published online: 26 June 2012

(C) INRA / Springer-Verlag France 2012

\begin{abstract}
- Context Customers have limited tolerances for colour differences between oak wood elements in parquetry or furniture, whereas manufacturers are in need of an objective method to communicate possible differences in their products.

- Aims This study is aimed at grading oak wood boards in objectively defined colour classes in correspondence with the visual assessment by an expert panel.

- Methods First, the most suitable spectrophotometer for measurements approximating the perception of the human eye was selected. Then, three colour grading algorithms were evaluated: one based on the smallest distance towards the centre of the colour subspaces, the second using a classification
\end{abstract}

\section{Handling Editor: Barry Alan Gardiner}

Contribution of the co-authors Nele Defoirdt: colour measurements, running the data analysis and writing the paper.

Inge Wuijtens: designing the experiment, coordinating the research

project, colour measurements, running the data analysis and reviewing the paper.

Lieven De Boever: designing the experiment, supervising the work, running the data analysis.

Hugo Coppens: supervising the work and reviewing the paper. Jan Van den Bulcke: supervising the work and reviewing the paper. Joris Van Acker: supervising the work and reviewing the paper.

N. Defoirdt $(\bowtie) \cdot J$. Van den Bulcke $\cdot$ J. Van Acker

Laboratory of Wood Technology, Department of Forest

and Water Management, Faculty of Bioscience Engineering,

Ghent University,

Coupure Links 653,

9000 Ghent, Belgium

e-mail: Nele.Defoirdt@UGent.be

I. Wuijtens $\cdot$ L. De Boever $\cdot$ H. Coppens

CTIB-TCHN (The Belgian Institute for Wood Technology),

Allée Hof ter Vleest 3,

1070 Brussels, Belgium tree and the last implementing the CIEDE2000 colour difference formula to determine tolerance ellipsoids.

- Results Statistical analysis using a classification tree and CIEDE2000 tolerance ellipsoids classified the specimens in good accordance with visual assessment, with a 6 and $5 \%$ misclassification, respectively.

- Conclusions The colour grading methodology can be adapted to particular grading purposes and is proposed as a basis for development of an inline colour grading system to be added to commonly used defect detection scanners.

Keywords Colour measurement · Oak wood · Colour grading $\cdot$ CIEDE2000

\section{Introduction}

Although colour variations are inherent to a biological material such as wood, customers do have certain tolerance limits for colour differences within a product. To meet the wishes of the end users, the manufacturing process may include a visual colour assessment; however, sorting colour manually is labour intensive and prone to the limits of subjective perception regarding colour uniformity of wooden elements in a product.

Objective colour measurements of wood have been used in several research projects. Janin et al. (1990), Klumpers and Janin (1992) and Winnock et al. (2010) for example studied the colour of oak wood, related to the age and annual ring width. Stokke et al. (1995) and Phelps et al. (1994) used colour measuring to select lighter white oak, which is commercially preferred, and the latter also developed a technique for improving colour matches in panel batches. The effect of weathering and thermal treatments on colour changes was the subject of several studies (among 
others Brischke et al. 2007; Pandey 2005; Stenudd 2004; Sundqvist 2002; Temiz et al. 2005). Unfortunately, most reports lack detailed description of the methodology used, whereas a general methodology to determine wood colour would be a useful addition to existing research.

A standardized objective assessment based on an automated colour grading system could enhance the manufacturer's turnover, reduce the loss of raw material by better selection, anticipate on customer expectations and increase the use of wood of lower quality to reach a higher yield. Automated scanners or cameras for defect detection are available and commonly used in the woodworking industry, but colour grading systems are not common. Researchers at the Virginia Tech University (Department of Electrical and Computer Engineering and Department of Wood Science and Forest products), together with members of NOVA Technologies (North Carolina), developed an automated colour sorting system for hardwood edge-glued panel parts (Srikanteswara et al. 1997). The software of this system used 3D colour histograms of red, green, blue (RGB) values obtained by colour cameras, which needed data reduction to allow real-time operations risking loss of essential colour information. Furthermore, Katuščák and Kucera (2000) consider the RGB colour model less appropriate and selected the CIE $L^{*} a^{*} b^{*}$ space as the most suitable for wood colour communication.

The industry active in oak wood parquetry and furniture production indicated that customers not only prefer lighter oak wood, but also often complain about a differing hue of adjacent elements, e.g. a more pinkish element in a rather brownish product. Therefore, the goal of this study was to develop an objective grading algorithm to classify oak wood in more homogeneous classes according to a measuring methodology that can be used as a basis for automation. Defining such algorithm requires in the first place that colour differences observed with the human eye are detectable in objectively measured colour data. The measuring methodology includes the selection of the most favourable measuring device as well as optimising a grading technique to find the best accordance with the visual classification.

\section{Materials and methods}

\subsection{Oak wood material}

One hundred thirty-nine specimens of quarter- and intermediatesawn and planed parquet strips of European oak wood (Quercus sp.) were selected from various production batches. The air-dry strips measured $400 \times 70 \times 10 \mathrm{~mm}$ and were graded as belonging to the best quality class according to the Benelux classification, which is even more stringent than in the European standard EN 13227
(2002). At a parquet production factory, the organisers of the visual assessment observed specimens in a light cabinet (see Section 2.2) to select a similar amount of specimens with a brownish and pinkish hue for the assessment, and a typical brownish and pinkish reference specimen was also chosen. The specimens were shielded from light to prevent colour changes until colour measurements started.

\subsection{Visual assessment}

To assess surface colours in a defined and reproducible way, a standardized light cabinet with a neutral grey background (Munsell N7) and equipped with a D65 standard illuminant perpendicular to the surface was used. The observer assessed the specimens parallel to the longitudinal direction of the specimens and at an angle of $45^{\circ}$ without interference from the outside environment. Five adequate observers having knowledge of wood were trained and classified the strips in the brownish or the pinkish group in accordance with the reference specimens. Each observer assessed all specimens three times, and all specimens had to be classified into one of the groups. After the visual classification was achieved, the variability between observers was determined by calculating Siegel and Castellan's fixed-marginal multirater kappa (Siegel and Castellan 1988). As the authors consider the visual classification to be 'correct', specimens are labelled correct or incorrect by the grading algorithms, respectively, when there is or there is no agreement with visual classification.

\subsection{Spectrophotometer measurements}

As spectrophotometers register more detailed information compared to tristimulus colorimeters, they are usually preferred for research (Stokke et al. 1995). The object is illuminated with a standard light source, and the intensity of reflected light is measured in discrete wavelength intervals of the spectrum. The device software calculates the coordinates of the CIE $L^{*} a^{*} b^{*}$ or CIE $L^{*} C^{*} h_{a b}$ colour space starting from the determined tristimulus values for the

Table 1 Spectrophotometers used in this study with their specific aperture size and measuring geometry

\begin{tabular}{lll}
\hline Spectrophotometer & $\begin{array}{l}\text { Diameter measuring } \\
\text { aperture }(\mathrm{mm})\end{array}$ & $\begin{array}{l}\text { Measuring } \\
\text { geometry }\end{array}$ \\
\hline Labscan XE & 44 & $0^{\circ} / 45^{\circ}$ \\
& 25 & $0^{\circ} / 45^{\circ}$ \\
Ultrascan Pro & $19 / 25^{\mathrm{a}}$ & $\mathrm{d} / 8^{\circ}$ \\
Konica Minolta & $3 / 6^{\mathrm{a}}$ & $\mathrm{d} / 8^{\circ}$ \\
CM2600-d & $8 / 11^{\mathrm{a}}$ & $\mathrm{d} / 8^{\circ}$ \\
\hline
\end{tabular}

${ }^{a}$ Diameter of measured circle/diameter of measuring aperture 
Fig. 1 Position of the measurements: $\mathbf{a}$ in relation to other apertures, $\mathbf{b}$ on the parquet strips

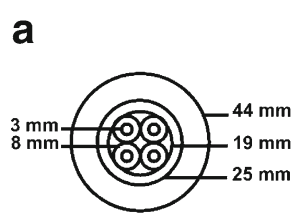

b

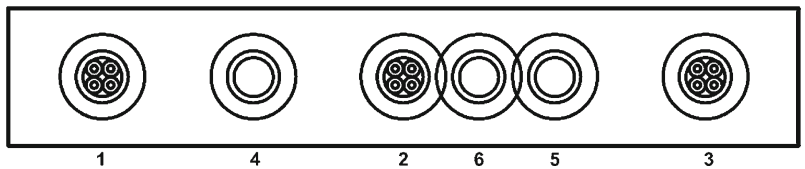

specific illumination used. Detailed information about these colour spaces is given in ISO 11664-4 (2008). All spectrophotometers mentioned in Table 1 were used to measure the parquet strips, using the same D65 standard illuminant and a standard observer of $10^{\circ}$, but differing in measuring aperture and geometry. A specific position of the measurements (Fig. 1) allowed the comparison of several measurements with small aperture to one measurement with a large aperture. Statistical comparison of different apertures or geometries was done on $L^{*} a^{*} b^{*}$ or $L^{*} C^{*} h_{a b}$ values with paired $t$ tests or with non-parametric Wilcoxon signed-rank tests. For the correspondence with visual assessment, a multivariate hierarchical clustering (agglomerative nesting with Ward's method) of these values was performed, and the spectrophotometer having the highest correspondence with visual classification was retained for further analyses in this paper. A multivariate analysis of variance with Wilk's lambda test showed whether the measurements of the pinkish and brownish colour groups differed significantly. Furthermore, a principal component analysis (PCA, Jolliffe 2002), which transforms the variables into principal components, reveals the colour parameters explaining the largest variance in the dataset. All statistical tests were performed in S-PLUS 8.0 using a significance level of $5 \%$.

A colour space of European oak wood and the pinkish and brownish subspaces within the CIE $L^{*} a^{*} b^{*}$ and CIE $L^{*} C^{*} h_{a b}$ colour space could be determined. Therefore, the mean colour of each strip was computed with the least square method as the theoretical centre that has the smallest sum of distances to all measurements on the strip. The centre of the oak colour spaces was then determined as the point with the smallest sum of distances to all centres of the strips. Analogously the centres of the pinkish and brownish subspaces were calculated considering respectively the pinkish and brownish strips. The standard deviation of $L^{*}$, $a^{*}, b^{*}, C^{*}$ and $h_{a b}$ was also determined to describe the subspaces.

\subsection{Grading according to colour}

Three different colour grading algorithms were tried to label the parquet strips. First, the smallest distance to one of the centres of the subspaces was used to classify the colour. Secondly, statistical classification by means of a classification tree, a non-parametric technique, divided the space of the multivariate results (variables $L^{*}, a^{*}, b^{*}, C^{*}$ and $h_{a b}$ ) into groups based on the homogeneity of the newly composed groups. The probability of a strip to belong to one of the two groups can be calculated by the mean and standard deviation of the measurements as

$P(p \leq x)=P\left(\frac{x-m}{s} \leq Z\right)$

with $p$ the parameter determining the first condition split in the classification tree, $x$ the level of $p$ at the split, $m$ and $s$ the mean and standard deviation of the measurements on the strip, respectively, and $Z$ the corresponding value on the standard normal probability density function curve. The probability to belong to the other group is then $1-P(p \leq x)$.

Third, classification was accomplished by calculating an acceptable $\Delta E_{00}$ value with respect to the colour group centre. The CIEDE2000 colour difference equation defines a colour difference $\Delta E_{00}$ that weighs the colour parameters according to their visual importance in human colour perception. In contrast with the simple $\Delta E^{*}, \Delta E_{00}$ is independent of the position in the colour space and calculated as follows:

$\Delta E_{00}=\sqrt{\left(\frac{\Delta L^{\prime}}{k_{L} S_{L}}\right)^{2}+\left(\frac{\Delta C^{\prime}}{k_{C} S_{C}}\right)^{2}+\left(\frac{\Delta H^{\prime}}{k_{H} S_{H}}\right)^{2}+R_{T}\left(\frac{\Delta C^{\prime}}{k_{C} S_{C}}\right)\left(\frac{\Delta H^{\prime}}{k_{H} S_{H}}\right)}$

with $S_{L}, S_{C}$ and $S_{H}$ as adjustment factors for $L^{*}, C^{*}$ and $h_{a b}$, respectively, which improves the lack of uniformity of the CIE $L^{*} a^{*} b^{*}$ colour space and $k_{L}, k_{C}$ and $k_{H}$ as parametric weighting factors considering variation in experimental conditions such as luminance level, background colour, texture, etc. $R_{T}$ is the rotation term that is different from zero only in the blue region (Huertas et al. 2006; Luo 2002; Kandi and Tehran 2009). For a complete description of all parameters, we refer to the publications of CIE (2001) and Sharma et al. (2005).

In the present study, the optimal parametric factors $k_{L}, k_{C}$ and $k_{H}$ as well as the optimal $\Delta E_{00}$ level that separates the pinkish and brownish specimens were searched for. For homogeneous materials, the parametric factors are all set to 1 , whereas the texture of textiles requires $k_{L}$ to be 2 (Kandi and Tehran 2009). As the appearance of wood is also strongly determined by its texture, most likely, not all parametric factors are equal to 1. Hauptmann et al. (2011) had better results with $\Delta E_{00}(2: 1: 1)$ than with $\Delta E_{00}(1: 1: 1)$ in their study with oak wood. The common determination of the parametric factors, by comparing visual colour differences with the corresponding $\Delta E_{00}$ (Xin et al. 2001), is unfeasible for wood as a visual colour difference scale is difficult to compose. Therefore, the $\Delta E_{00}$ between all visual 
assessed specimens and the pinkish centre $\left(\Delta E_{00 \text {,pink }}\right)$ as well as the brownish centre $\left(\Delta E_{00, \text { brown }}\right)$ were calculated for several combinations of parametric factors, and those two variables were used to make a classification tree to determine the $\Delta E_{00}$ level at which pinkish and brownish specimens are separated. The $\Delta E_{00 \text {,pink }}$ or $\Delta E_{00 \text {, brown level }}$ that determined the split of the tree was considered as the general $\Delta E_{00}$ to be used. For each combination of parametric factors and $\Delta E_{00}$, the success rate (i.e. objective classification agreeing with visual classification) was calculated, and the best combination was selected.

\section{Results}

\subsection{Visual assessment}

It is obvious that the degree of consensus was inversely proportional to the number of observers taken into account (Table 2). Specimens classified three times in the same class by all observers are model specimens for their colour class, whereas specimens classified in the same class by only $60 \%$ of the observers are mostly located at the borders of their colour class, as such in close vicinity to the borders of another colour class. The dataset containing the specimens which were classified equally by $60 \%$ of the observers (108 samples) was the one used for further statistical analysis as groups with sufficient within variation were formed with this assessment. Siegel and Castellan's fixed-marginal multirater kappa was 0.75 which is above the limit of 0.70 that indicates adequate interrater agreement.

\subsection{Spectrophotometer measurements}

There was a considerable effect of the used measuring aperture for the measurements (Table 3 ). Clustering $L^{*} a^{*} b^{*}$ values showed less similarity with visual classification than clustering the $L^{*} C^{*} h_{a b}$ values. When larger tolerance limits were allowed (i.e. less observers had to agree upon a classification), measurements performed with a larger aperture showed more similarity and on a higher cluster level with the visual classification (Fig. 2). On the contrary,

Table 2 Number of specimens of each colour class according to 100 , 80 and $60 \%$ of the observers (fractions between brackets)

\begin{tabular}{llll}
\hline & \multicolumn{2}{l}{ Fraction of the observers (\%) } \\
\cline { 2 - 4 } & 100 & 80 & 60 \\
\hline Consensus: brownish & $26(19 \%)$ & $50(36 \%)$ & $59(42 \%)$ \\
Consensus: pinkish & $21(15 \%)$ & $31(22 \%)$ & $49(36 \%)$ \\
No consensus & $92(66 \%)$ & $58(42 \%)$ & $31(22 \%)$ \\
\hline
\end{tabular}

Table 3 Comparison of various spectrophotometer apertures

\begin{tabular}{ll}
\hline Compared apertures & Significantly different colour parameters \\
\hline$<10$ vs. $>10 \mathrm{~mm}$ & $L^{*}, a^{*}, b^{*}, C^{*}, h_{a b}$ \\
3 vs. $8 \mathrm{~mm}$ & $a^{*}, b^{*}, C^{*}$ \\
25 vs. $44 \mathrm{~mm}$ & $L^{*}, a^{*}, C^{*}, h_{a b}$ \\
\hline
\end{tabular}

when only a small tolerance limit was allowed (i.e. only those specimens were considered for which all observers agreed on their colour class), small measuring apertures seemed to be more appropriate. Another measuring geometry also caused significant differences in the measured information, but the clustering gave no evidence for any preference. However, colour technologists report that $0 \%$ $45^{\circ}$ or $45^{\circ} / 0^{\circ}$ geometry simulates the visual experience better (Chrisment 2004; Hunter and Harold 1987).

Within the framework of this study, the use of a larger measurement aperture was preferred as division into only two groups was intended, and therefore, relatively large tolerances were used. A classification in more groups was not requested by the industry nor by the consumers. Therefore, statistical analysis discussed in the rest of this paper refers to measurements with the Labscan XE.

Centres and standard deviations of the measured oak colour space and the pinkish and brownish subspaces are listed in Table 4. A significant difference between the pinkish and brownish group was statistically discernible, which means that these objectively determined colour parameters can be used for an automated colour grading in accordance with visually detectable differences. In PCA analyses with $L^{*}, a^{*}, b^{*}, C^{*}$ and $h_{a b}$, two components explained $89 \%$ of the total variance in the dataset. These components are:

component $1=0.85 L^{*}+0.47 h_{a b}-0.21 a^{*}-0.09 C^{*}-0.02 b^{*}$ component $2=-0.78 h_{a b}+0.53 L^{*}+0.33 a^{*}+0.07 C^{*}-0.03 b^{*}$

and the biplot (Fig. 3) shows that $a^{*}, b^{*}, C^{*}$ and $h_{a b}$ were closely correlated (small angles between the arrows) and that $L^{*}$ and $h_{a b}$ had the largest variability (longest arrows). The biplot also shows that the two colour groups were distinguishable, even though there was a transition zone. The distinction followed the variation in $h_{a b}$, increasing from pinkish to brownish specimens.

\subsection{Grading according to colour}

Classification according to the smallest distances to the subspace centres classified only $72 \%$ of the specimens correctly. Secondly the first split condition of the classification tree defined strips with a mean $h_{a b}$ value smaller than 71.14 as pinkish (Fig. 4), although this branch still contained $10 \%$ of the brown specimens. The power of the 


\section{a}

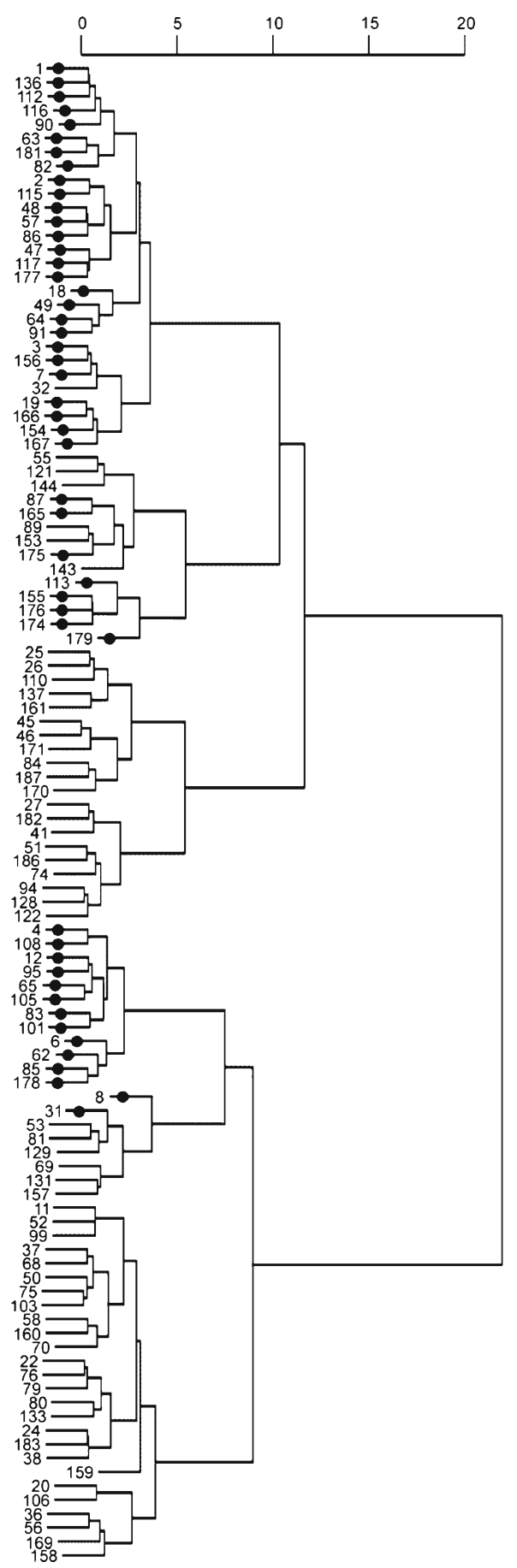

Fig. 2 Clustering of 108 specimens based on the $L^{*}, C^{*}$ and $h_{a b}$ values measured with spectrophotometers: a Konica Minolta with 8 $\mathrm{mm}$ aperture, $\mathbf{b}$ Labscan with $25-\mathrm{mm}$ aperture; visual assessment $(60 \%$

tree was evaluated by calculating the probabilities of the strips to be smaller or larger than 71.14. Ninety-eight percent of the strips had a probability higher than $75 \%$ to be pinkish or brownish, and $91 \%$ even had a probability higher than $95 \%$. With this second classification method, only $6 \%$ of the specimens were wrongly classified.

\section{b Height}

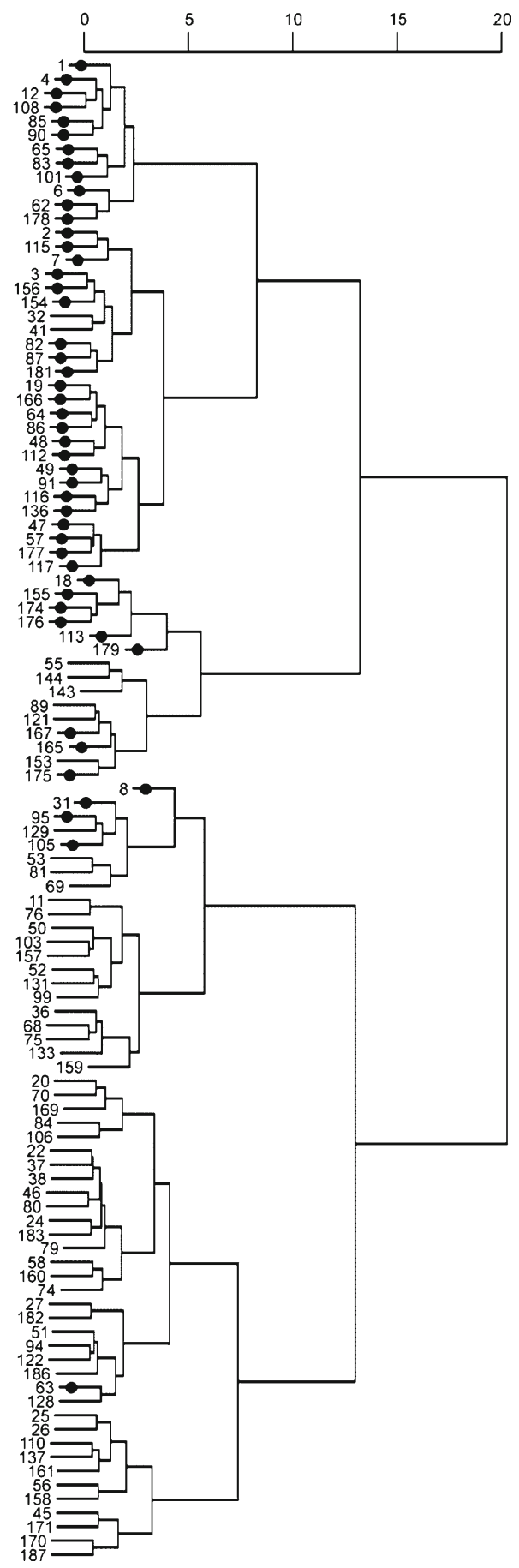

of the observers considered) is indicated: pinkish specimens have dots, brownish specimens have no dots

The best results for the CIEDE2000 method were obtained with the combination of the parametric factors $K_{L}=6, K_{C}=4$, $K_{H}=1$ and a $\Delta E_{00}$ level of 0.5 for separating pinkish and brownish groups. Figure 5 illustrates the CIEDE2000 approach. Eighty-four percent of the specimens were included in the correct ellipsoid, and $5 \%$ were falsely labelled pinkish. 
Table 4 European oak colour space and subspace centres and standard deviations of the colour parameters

\begin{tabular}{llllll}
\hline Colour space & $L^{*}$ & $a^{*}$ & $b^{*}$ & $C^{*}$ & $h_{a b}$ \\
\hline Oak & $67.0 \pm 1.8$ & $7.6 \pm 0.4$ & $22.2 \pm 0.5$ & $23.4 \pm 0.6$ & $71.1 \pm 0.8$ \\
Pinkish oak & $66.7 \pm 1.9$ & $8.1 \pm 0.4$ & $22.0 \pm 0.5$ & $23.5 \pm 0.6$ & $69.8 \pm 0.8$ \\
Brownish oak & $67.1 \pm 1.8$ & $7.2 \pm 0.4$ & $22.2 \pm 0.6$ & $23.4 \pm 0.7$ & $72.1 \pm 0.9$ \\
\hline
\end{tabular}

Another $5 \%$ of the specimens were situated outside the ellipsoids, but far away from the transition zone between pinkish and brownish samples. So although these specimens had another colour according to the CIEDE2000 theory, they could clearly be attributed to the pinkish or brownish group in accordance with the classification tree if $h_{a b}$ was either 0.5 degree larger or 0.5 degree smaller than 71.14. Other excluded specimens $(6 \%)$ were real borderline cases and thus difficult to classify.

\section{Discussion}

The spectrophotometer used for colour grading was a Labscan XE, using a $10^{\circ}$ standard observer, D65 standard illuminant and $45^{\circ} / 0^{\circ}$ measuring geometry. Other standard observers ( $2^{\circ}$ in Katušč́k et al. 2002), standard illuminants (C in Stenudd 2004) and device geometries ( $d / 8^{\circ}$ in Pandey 2005; d $/ 0^{\circ}$ in Katušćák et al. 2002) are used for wood colour determination. Often, these instrument settings, which are indispensable for comparing results, are missing in publications. Furthermore, a rather large measuring aperture $(25 \mathrm{~mm})$ seemed more appropriate for classification into two groups. This device parameter is not always mentioned in the literature. Reported apertures vary from $8 \mathrm{~mm}$ up to

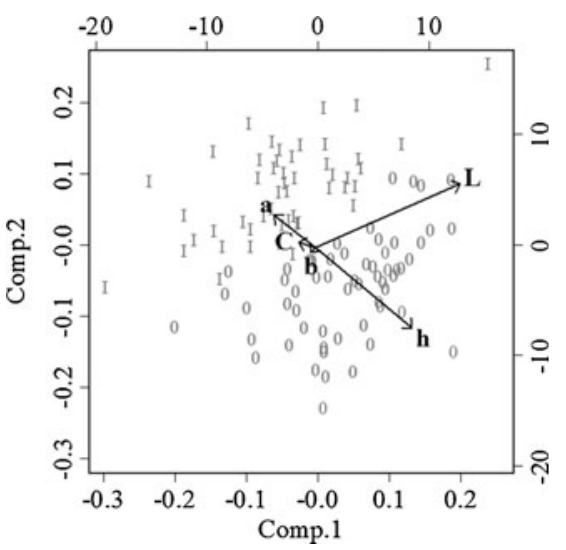

Fig. 3 Biplot of the principal component analysis of the colour parameters measured on visually assessed parquetry strips: $I$ pinkish and $O$ brownish specimens. The principal components are a linear combination of the measured variables $L^{*}, a^{*}, b^{*}, C^{*}$ and $h_{a b}$ indicated on the plot

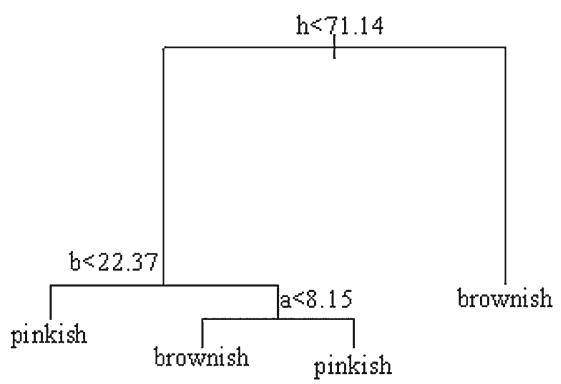

Fig. 4 Classification tree based on $L^{*}, a^{*}, b^{*}, C^{*}$ and $h_{a b}$ values of 108 visually assessed parquet strips

50 mm (Katuščák et al. 2002; Stenudd 2004; Sundqvist 2002), but the choice of the aperture is mostly not explained.

Concerning the grading algorithms used in this study, the training phase includes visual assessment of a representative set of material to define the desired colour subspaces. Alternatively, the visual assessment could be replaced by an objective tool-chain: as an experiment, the labelling of the training specimens was done by clustering the specimens according to the spectrophotometer measurements. For the latter, the weighing factors of the CIEDE2000 method were taken into account as they describe the mutual importance of the colour parameters. The clustering was thus performed with the $L^{*} / 6, C^{* / 4}$ and $h_{a b}$ values. Based on this labelling of the training set that had $94 \%$ accordance with the visual grading, the centres of the subspaces were calculated as well as a classification tree (similar to Fig. 4) indicating that the two groups were divided by the same $h_{a b}$ limit value of 71.14. Evaluation of this fully objective grading was done according to the visual assessment available in this study: classification by the latter tree had $94 \%$ of the specimens labelled correctly, and $86 \%$ of the specimens were situated in the tolerance ellipsoids around the subspace centres in accordance with the visual assessment, with only

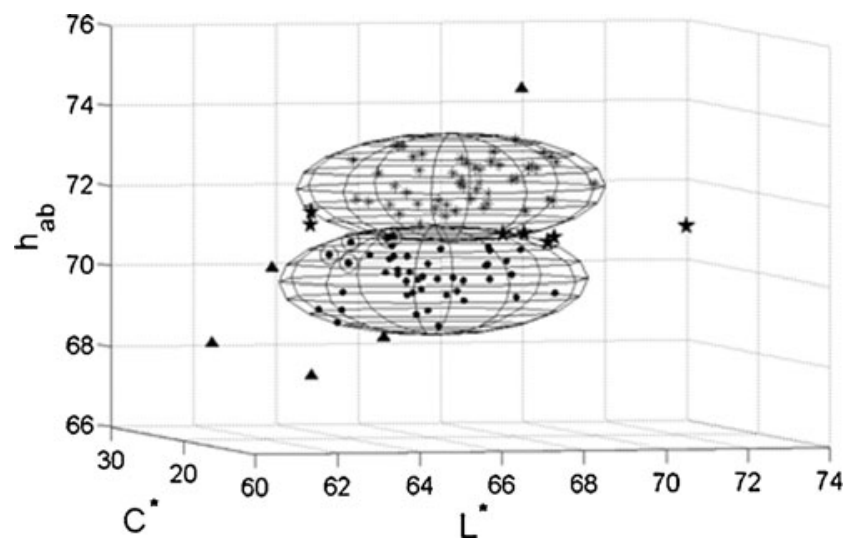

Fig. 5 Visually assessed parquet strips situated in relation to the $\Delta E_{00}$ ellipsoids around the pinkish and brownish centres; strips in the ellipsoids: asterisks brownish, dots pinkish — specimens not in accordance with visual assessment are circled; strips outside the ellipsoids: triangles obviously at one colour side, stars difficult to classify 
$5 \%$ in the 'wrong' ellipsoid. Six percent of the specimens were outside the tolerance ellipsoids but clearly positioned at one colour side or the other $\left(h_{a b}\right.$ more than 0.5 degree smaller or larger than 71.14). Five percent were located in between the two ellipsoids and therefore hard to classify. In this test case, starting from objectively determined colour groups did not lower the number of correctly labelled specimens compared to the grading methodology that was based on visually determined colour groups.

In conclusion, implementation of the developed grading systems in a processing facility could be done as follows: A training set is sorted into colour groups by visual assessment or clustering of the weighed spectrophotometer measurements, and a classification tree is constructed and/or the $\Delta E_{00}$ tolerance ellipsoids are calculated. Then, the evaluation set is sorted into colour groups according to the classification tree and/or the position with respect to the $\Delta E_{00}$ tolerance ellipsoids. Moreover, one could even think of an interactive tool to define an individual colour subspace preferred by a customer, adding colour as an extra dimension for tailor-made pieces.

Some issues concerning the grading algorithm with CIEDE2000 and the implementation need more refinement in the future. The approach for wood shows some similarity with the application of the method on textiles. The texture of the sample is one of the most important parametric criteria linked to the parametric factors of the equation (Kandi and Tehran 2009). Montag and Berns (2000) found that for textiles, texture increases the $L^{*}$ tolerance threshold by a factor of almost 2 compared to uniform stimuli, and Huertas et al. (2006) showed that for random-dot textures, the tolerance on $L^{*}$ is increased the most, but also warned that the influence of texture on $C^{*}$ and $h_{a b}$ tolerances is in general not negligible. The latter also report that each texture or sort of texture should be studied separately in this context. The proposed parametric factors determined in the present study surely need confirmation by more research on other datasets, but they are in accordance with human perception as being most tolerant in $L^{*}$, intermediately tolerant in $C^{*}$ and least tolerant for $h_{a b}$ deviations (Malacara 2002). Furthermore, the determined $\Delta E_{00}$ level is open to discussion. The chosen level had the best accordance with the visual assessment, which forced the observers to choose between the brownish and pinkish hue. Enlarging the $\Delta E_{00}$ tolerance level would make specimens currently located outside the tolerance ellipsoids but clearly at the brownish or pinkish side of the colour space, included in the larger tolerance ellipsoids. On the other hand, more specimens situated at the transition zone could then be included in the overlap of both tolerance ellipsoids meaning that they fit into both colour groups. In contrast, a choice of smaller ellipsoids would cause specimens clearly at the brownish or pinkish side of the colour space but too far away from the centres of the ellipsoids to be excluded. The possibility to adapt the $\Delta E_{00}$ level to each particular purpose makes CIEDE2000 a very strong tool.

Implementation as a continuous inline system, such as the sorting system developed at the Virginia Tech University and NOVA Technologies (Srikanteswara et al. 1997), must be feasible. This requires the combination of a well known and stable light source and an appropriate camera system. Exploratory experiments (unpublished results) consisted in the calibration of a scanning system using standard colour charts that were scanned and measured with a spectrophotometer as described in Léon et al. (2006). Promising first results demonstrated that it is possible to use a scanner or camera that registers RGB values and transform these values to $L^{*} a^{*} b^{*}$ or $L^{*} C^{*} h_{a b}$ values used for colour grading as described in this paper. As camera or scanner systems are already used in production processes for defect detection, the addition of an extra inline scanner unit for colour grading or additional software in combination with existing scanner systems would be useful for manufacturers.

\section{Conclusion}

The aperture of the spectrophotometer influences the measured results significantly, but as the objective in this study was a coarse classification between only two classes, a relatively larger aperture was preferred. Concerning the measuring geometry of the spectrophotometers, no preference could be determined. Differences between the visually distinct groups were significant in the objectively assessed colour parameters, with more correspondence when $L^{*} C^{*} h_{a b}$ values were considered. The most important parameters for grading were $L^{*}$ and $h_{a b}$. The importance of $h_{a b}$ was confirmed, as the first split condition in the classification tree used the $h_{a b}$ values. Using the classification tree resulted in a misclassification of $6 \%$, whereas using a $\Delta E_{00}(6: 4: 1)$ level of 0.5 to define tolerance ellipsoids classified $5 \%$ wrongly. The $\Delta E_{00}$ level may be adapted to each particular purpose and is as such a very strong and flexible approach for colour classification. This study demonstrates the potential for automated colour grading of oak wood in the woodworking industry and suggests that even the use of a camera system added to common defect detection scanners would make grading pre-sawn elements possible as well as colour-guided sawing of larger elements.

Funding The authors wish to thank IWT (Agency for Innovation by Science and Technology) of the Flemish Government for financing this project and the members of the users group for their constructive advice. The authors are also grateful to the Research Foundation Flanders (FWO) for the postdoctoral grant of Jan Van den Bulcke. 


\section{References}

Brischke C, Welzbacher CR, Brandt K, Rapp AO (2007) Quality control of thermally modified timber: interrelationship between heat treatment intensities and CIE L*a*b* color data on homogenized wood samples. Holzforschung 61:19-22

Chrisment A (2004) Le Guide de la Couleur n³. Connaître et comprendre la colorimétrie. Editions $3 \mathrm{C}$, Paris.

CIE (2001) Improvement to industrial colour difference evaluation. CIE Publ. No 142, Central Bureau of the CIE, Vienna.

EN 13227, (2002) Wood flooring - solid lamparquet products. European Committee for Standardization, Brussels

Hauptmann M, Pleschberger H, Mai C, Follrich J, Hansmann C (2011) The potential of color measurements with the CIEDE2000 equation in wood science. Eur J Wood Prod. doi:10.1007/s0010701105756

Huertas R, Melgosa M, Hita E (2006) Influence or random-dot textures on perception of suprathreshold color differences. J Opt Soc Am A 23:2067-2076

Hunter RS, Harold RW (1987) The measurement of appearance. Wiley, New York

ISO 11664-4 (2008) Colorimetry-part 4: CIE 1976 L*a*b* colour space. International Organization for Standardization, Geneva

Janin G, Mazet JF, Flot JL, Hofmann P (1990) Couleur et qualité du bois de chêne de tranchage: chêne sessile, chêne pédonculé et chêne rouge. Revue Forestière Française 42:134-139

Jolliffe IT (2002) Principal component analysis (2nd ed). Springer, New York

Kandi SG, Tehran MA (2009) Investigating the effect of texture on the performance of color difference formulae. Color Res Appl 35:94-100

Katušćák S, Kucera LJ (2000) CIE orthogonal and cylindrical color parameters and the color sequences of the temperate wood species. Drev Vysk 45:9-22

Katuščák S, Kucera LJ, Varga Š, Vrška M, Čeppan M, Šutý Š, Jablonský M (2002) New method of recognition of wood species. Increasing of the effectiveness of colorimetric recognition of Picea excelsa and Abies alba. Drev Vysk 47:1-12

Klumpers J, Janin G (1992) Influence of age and annual ring width on the wood color of oaks. Holz Roh Werkst 50:167-171

Léon K, Mery D, Pedreschi F, León J (2006) Color measurement in L*a*b* units from RGB digital images. Food Res Int 39:1084-1091
Luo MR (2002) Development of colour difference formulae. Rev Prog Color 32:28-39

Malacara D (2002) Color vision and colorimetry: theory and applications. SPIE, The International Society for Optical Engineering, Bellingham

Montag ED, Berns RS (2000) Lightness dependencies and the effect of texture on suprathreshold lightness tolerances. Color Res Appl $25: 241-249$

Pandey KK (2005) A note on the influence of extractives on the photodiscoloration and photo-degradation of wood. Polym Degrad Stabil 87:375-379

Phelps JE, Stokke DD, Pugel AD (1994) Color analysis of white oak, edge-glued furniture panel stock. Forest Prod J 44:35-38

Sharma G, Wu W, Dalal EN (2005) The CIEDE2000 color-difference formula: implementation notes, supplementary test data, and mathematical observations. Color Res Appl 30:21-30

Siegel S, Castellan N (1988) Nonparametric statistics for the social sciences, 2nd edn. McGraw-Hill, New York

Srikanteswara S, Lu Q, King W, Drayer T, Conners R, Kline E, Araman P (1997) Real-time implementation of a color sorting system. In: SPIE-The International Society for Optical Engineering (ed.) Proceedings of SPIE, Washington, p 170-179.

Stenudd S (2004) Color response in silver birch during kiln-drying. Forest Prod J 54:31-36

Stokke DD, Pugel AD, Phelps JE (1995) Variation in lightness of white oak dimension stock. Forest Prod J 45:51-56

Sundqvist B (2002) Color response of Scots pine (Pinus sylvestris), Norway spruce (Picea abies) and birch (Betula pubescens) subjected to heat treatment in capillary phase. Holz Roh Werkst 60:106-114

Temiz A, Yildiz UC, Aydin I, Eikenes M, Alfredsen G, Çolakoglu G (2005) Surface roughness and color characteristics of wood treated with preservatives after accelerated weathering test. Appl Surf Sci 250:35-42

Winnock M, Defoirdt N, De Boever L, Van Acker J (2010) Impact of growth rate on the colour of oak. In: University of West Hungary and BOKU (eds.) Proceedings of "Hardwood science and technology". The 4th Conference on Hardwood Research and Utilisation in Europe, University of West Hungary, Sopron.

Xin JH, Lam CC, Luo MR (2001) Investigation of parametric effects using medium colour-difference pairs. Color Res Appl 26:376-383 